\title{
Development and Molecular Investigation into the Effects of Carbamazepine Exposure in the Zebrafish (Danio rerio)
}

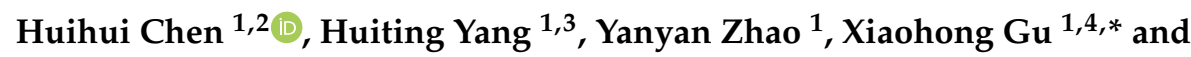 \\ Christopher J. Martyniuk ${ }^{5}$
}

1 State Key Laboratory of Lake Science and Environment, Nanjing Institute of Geography and Limnology, Chinese Academy of Sciences, Nanjing 210008, China; hhchen@niglas.ac.cn (H.C.); htyang305@gmail.com (H.Y.); yyzhao@niglas.ac.cn (Y.Z.)

2 State Key Laboratory of Developmental Biology of Freshwater Fish, College of Life Sciences, Hunan Normal University, Changsha 410081, China

3 Inner Mongolia Key Laboratory of Environmental Pollution Control \& Waste Resource Reuse, School of Ecology and Environment, Inner Mongolia University, Hohhot 010021, China

4 Jiangsu Collaborative Innovation Center of Regional Modern Agriculture \& Environmental Protection, Huaiyin Normal University, Huaian 223300, China

5 Department of Physiological Sciences and Center for Environmental and Human Toxicology, University of Florida Genetics Institute, Interdisciplinary Program in Biomedical Sciences Neuroscience, College of Veterinary Medicine, University of Florida, Gainesville, FL 32611, USA; cmartyn@ufl.edu

* Correspondence: xhgu@niglas.ac.cn

Received: 29 October 2020; Accepted: 26 November 2020; Published: 29 November 2020

\begin{abstract}
Concerns regarding environmental exposures and the impacts of pharmaceuticals on non-target aquatic organisms continue to increase. The antiepileptic drug carbamazepine (CBZ) is often detected as an aquatic contaminant and can disrupt various behaviors of fishes. However, there are few reports which investigate the mechanism of CBZ action in fish. The aim of the current study was to evaluate the effects of CBZ on embryonic development (i.e., hatching rate, heart rate, and body length) and early spontaneous movement. Moreover, we sought to investigate potential mechanisms by focusing on the gamma-aminobutyric acid (GABA) neurotransmitter system in zebrafish 6 days after of exposure. The results show that CBZ exposure did not cause significant effects on embryo development (hatching rate, heart rate, nor body length) at the test concentrations. However, the early spontaneous movement of embryos was inhibited following $10 \mu \mathrm{g} / \mathrm{L} \mathrm{CBZ}$ exposure at 28-29 h post-fertilization (hpf). In addition, acetylcholinesterase (AChE) activity and GABA concentrations were increased with exposure, whereas glutamate (Glu) concentrations were decreased in larval zebrafish. Gene expression analysis revealed that GABA and glutamate metabolic pathways in zebrafish larvae were altered following exposure to CBZ. GABA transaminase (abat) and glutamic acid decarboxylase (gad1b) decreased to $100 \mu \mathrm{g} / \mathrm{L}$, and glutamate receptor, ionotropic, N-methyl D-aspartate $1 \mathrm{~b}$ (grin $1 b$ ) as well as the glutamate receptor, ionotropic, $\alpha$-amino-3hydroxy-5methylisoxazole-4propionic $2 \mathrm{~b}$ (gria $2 b$ ) were down-regulated with exposure to $1 \mu \mathrm{g} / \mathrm{L} \mathrm{CBZ}$. Our study suggests that CBZ, which can act as an agonist of the $\mathrm{GABA}_{\mathrm{A}}$ receptor in humans, can also induce alterations in the GABAergic system in fish. Overall, this study improves understanding of the neurotoxicity and behavioral toxicity of zebrafish exposed to CBZ and generates data to be used to understand mechanisms of action that may underlie antiepileptic drug exposures.
\end{abstract}

Keywords: pharmaceuticals; carbamazepine; Danio rerio; gamma-aminobutyric acid; glutamate 


\section{Introduction}

Pharmaceuticals are bioactive chemicals used by humans for personal health and agricultural enterprises to improve animal growth [1,2]. Due to their widespread use, a significant number of pharmaceuticals have been discharged into aquatic environments [3-5]. Carbamazepine (CBZ) is one of the most frequently used antiepileptic drugs worldwide [6,7]. Due to its prevalence in water bodies and its resistance to removal during the sewage treatment process, CBZ is also one of the most frequently detected pharmaceuticals in aquatic environments [8]. CBZ has been detected in the range of 0.03 to $11.6 \mu \mathrm{g} / \mathrm{L}$ in various water bodies all over the world [9-12]. For example, CBZ was detected in $95 \%$ of the water samples collected from different locations around the United States of America (U.S.A.), and the mean concentration of CBZ in samples was $\sim 350 \mathrm{ng} / \mathrm{L}$ [10]. Moreover, CBZ was detected and posed ecological risk at 20 different sites from the Baiyangding Lake and Taihu Lake areas in China, and the authors emphasized that more attention should be given to CBZ as an environmental contaminant [5]. Based on these and other studies, concerns regarding the impacts of CBZ on non-target aquatic organisms remain and warrant additional investigation.

Studies have demonstrated that CBZ can adversely affect non-target species in aquatic environments $[6,7,13,14]$. As vertebrates, fish are perhaps more susceptible to pharmaceutical exposure than invertebrates because pharmaceuticals are designed for human (vertebrate) use. Data on the toxic effects of CBZ on fish have been reported for different species, such as the zebrafish (Danio rerio), Chinese rare minnows (Gobiocypris rarus), and Japanese medaka (Oryzia latipeus) [15-20]. For example, $0.5 \mu \mathrm{g} / \mathrm{L}$ CBZ exposure increased embryo mortality, lowered plasma steroid hormone levels, and decreased egg production in zebrafish [21]. Moreover, $10 \mu \mathrm{g} / \mathrm{L} \mathrm{CBZ} \mathrm{exposure} \mathrm{can} \mathrm{affect} \mathrm{feeding} \mathrm{behavior} \mathrm{and} \mathrm{can}$ interfere with neurotransmission and the antioxidant system in zebrafish [16]. In addition, Yan et al. (2019) showed that CBZ may act as an endocrine disruptor in rare minnows [20]. Based on these studies, exposure to CBZ can adversely impact development, behavior and endocrine processes in fish. However, the underlying mechanisms of CBZ toxicity in fish are not well characterized.

Pharmaceuticals developed for human use often have well-established mechanisms of action (MoA), and as such, assessment of the effects of pharmaceutical drugs in aquatic animals should be based on their MoAs [22]. One of the MoAs of the antiepileptic drug CBZ in humans is related to the gamma-aminobutyric acid (GABA) neurotransmitter system [23]. GABA is the most abundant inhibitory neurotransmitter in the nervous system [24-26]. The GABA neurotransmitter system consists of several GABA receptor subtypes, each comprised of different subunits, as well as enzymes that synthesize and metabolize GABA [27]. Among the GABA receptors, $\mathrm{GABA}_{\mathrm{A}}$ receptor $\alpha 1$ (Gabra1) plays a pivotal role in mediating rapid inhibitory synaptic transmission in the central nervous system [28]. The glutamate receptors, such as the "glutamate receptor, ionotropic, N-methyl D-aspartate $1 \mathrm{~b}$ (Grin $1 \mathrm{~b})$ " and the "glutamate receptor, ionotropic, $\alpha$-amino-3hydroxy-5methylisoxazole-4propionic $2 b$ (gria2b)," are also related to neurobehavior in fish and are associated with GABA signaling [29] as glutamate acts as the metabolic precursor for GABA synthesis. Glutamate decarboxylase (Gad1b) and GABA transaminase (ABAT) are the two main enzymes involved in regulating glutamate-GABA metabolic pathways [30]. Many antiepileptic drugs bind to $\mathrm{GABA}_{A}$ receptors to enhance GABAergic signaling to exert inhibitory actions in the brain [25]. CBZ is known to modulate the release, uptake, and receptor binding of neurotransmitters, and it acts as an agonist to the $\mathrm{GABA}_{\mathrm{A}}$ receptor in humans [18]. However, most studies to date have not examined the MoA of CBZ in fish, and as a result, the potential ecological risks associated with CBZ may be underestimated.

As such, the effect of CBZ on the GABA neurotransmitter system in zebrafish was investigated in this study. Three nominal concentrations $(1,10,100 \mu \mathrm{g} / \mathrm{L})$ were used to study the toxicity of CBZ on zebrafish embryos. The lowest concentration targeted environmentally relevant levels of CBZ. The developmental toxicity of CBZ to zebrafish was first assessed, and several endpoints that included early spontaneous movement rate, hatching rate, heart rate, and body length were measured. Secondly, GABA and glutamate (Glu) concentrations, as well as transcript levels associated with GABA and glutamate receptor mRNA levels (gabra1, grin1b, and gria2b), and glutamate metabolic pathways (gad1b 
and abat) were determined in larval fish. Moreover, since acetylcholinesterase (AChE) is a widely used enzymatic biomarker of neurotoxicity and is often measured in studies to detect neurotoxic effects of various contaminants in the aquatic environment [31,32], AChE activity was also determined.

\section{Materials and Methods}

\subsection{Fish and Culture Conditions}

Adult zebrafish (wild-type AB strain) were cultured in a laboratory aquaculture system using aerated tap water. Fish were raised with a photoperiod of 14:10 h light: dark cycle and were fed with either live brine shrimp (Artemia nauplii) or a commercial fish diet on alternating days. For spawning, adult females and males (1:3) were placed into mating tanks. At $1-2 \mathrm{~h}$ post-fertilization (hpf), fertilized eggs from the same batch were examined by a stereomicroscope. The embryos that were developing normally were selected for subsequent experiments based upon staging outlined in Kimmel [33]. The fertilized eggs at shield stage ( $\sim 6 \mathrm{hpf})$ were used for exposure experiments. All experimental procedures involving fish were approved by the Institutional Animal Care and Use Committee of the Nanjing Institute of Geography and Limnology, Chinese Academy of Sciences. At the end of the experiment, all zebrafish larvae were euthanized in liquid nitrogen, and those larvae that did not survive were collected and properly treated as hazardous wastes.

\subsection{Exposure Proposal}

CBZ (purity $>97 \%$, J\&K Chemical Ltd., Shanghai, China) was first prepared in amber vials as a stock solution $(10 \mathrm{mg} / \mathrm{mL})$ in dimethylsulfoxide (DMSO). The CBZ stock solution was prepared fresh each week. Selected embryos that were developing normally were exposed to CBZ. There were four treatments with the final concentrations of 0 (control, treated with $0.001 \%(w / v)$ DMSO), 1 , 10 and $100 \mu \mathrm{g} / \mathrm{L}$ CBZ. The exposure solutions were prepared using the CBZ stock solution. The final DMSO concentration was $0.001 \%(v / v)$ in each group. There were two exposure experiments; one was conducted for development and gene expression, and a second exposure was conducted for enzyme-linked immunosorbent assay (ELISA) measurements. CBZ concentrations were quantified after the exposure solutions were dosed in the beaker or in the microplate each week according to our previously described method [6,14]. Briefly, for water samples, CBZ concentrations were quantified before and after water was refreshed. Water samples were filtered through $0.45 \mu \mathrm{m}$ glass fiber filters and extracted using Oasis HLB cartridges ( $6 \mathrm{~mL}, 200 \mathrm{mg}$; Waters Corporation, Milford, MA, USA). CBZ was quantified using ultra-performance liquid chromatography tandem mass spectrometry X-TQD (UPLC-MS/MS; Waters Corporation, Milford, MA, USA).

\subsubsection{Exposure Experiment 1}

Selected embryos from a single batch were randomly distributed among glass beakers ( $50 \mathrm{~mL}$ ) containing $10 \mathrm{~mL}$ exposure solution, and there were 20 embryos in each beaker. There were five replicate beakers for each treatment. The final exposure solutions were refreshed daily ( $90 \%$ change) during the $6 \mathrm{~d}$ exposure experiment. During the exposure period, zebrafish embryos were placed in a constant temperature incubator, the temperature was maintained at $27 \pm 1^{\circ} \mathrm{C}$, and the light dark cycle was $14 \mathrm{~h}: 10 \mathrm{~h}$ (day:night). During the exposure period, 16 zebrafish embryos were randomly selected from each treatment group to measure their autonomous movement at 28-29 hpf. The hatching rate of all zebrafish embryos in each treatment group was counted at $48-62 \mathrm{hpf}$. The heart rate and body length of 12 and 10 zebrafish larvae in each treatment group were measured at $72 \mathrm{hpf}$ and $96 \mathrm{hpf}$, respectively. After exposure, 5 larvae from each treatment group were collected and placed in a $1.5 \mathrm{~mL}$ centrifuge tube, frozen in liquid nitrogen, and stored at $-80^{\circ} \mathrm{C}$ for subsequent quantitative real-time PCR (RT-qPCR) analysis. 


\subsubsection{Exposure Experiment 2}

Exposure experiment 2 was carried out in a 12-well plate. Embryos ( 2400 embryos) were randomly transferred to 12-well Corning ultra-Low attachment microplates (Corning, NY, USA) (20 embryos per well) containing $4 \mathrm{~mL}$ of each exposure solution for $6 \mathrm{~d}$, and $90 \%$ exposure solutions were renewed every $24 \mathrm{~h}$. After $6 \mathrm{~d}$ exposure, 200 larvae in each treatment were collected and preserved as one biological replicate. Three biological replicates were constructed for each treatment $(n=3)$. After $6 \mathrm{~d}$ exposure, all the larvae were flash-frozen using liquid nitrogen and stored at $-80{ }^{\circ} \mathrm{C}$ for GABA and Glu concentrations and AChE activity analysis.

\subsection{Gene Expression Analysis}

After $6 \mathrm{~d}$ exposure, the transcript levels of genes associated with the GABA neurotransmitter system and glutamate metabolic pathways, including gabra1, grin $1 b$, gria $2 b$, abat, and gad $1 b$, were measured in the zebrafish larvae. RNA extraction, cDNA synthesis, and qPCR analysis were performed according to our previous methods [6]. Total RNA was isolated from larvae using TRIzol reagent (Invitrogen, Carlsbad, CA, USA). RNA quality and concentration were determined using BioTek Synergy HTX multi-function microplate (BioTek, VT, USA). RNA samples had a 260/280 nm absorption ratio $\geq 1.8$ and these samples were deemed high quality for further analysis. cDNA was synthesized using the FastKing cDNA First Strand Synthesis Kit (Tiangen, Beijing, China) from 500 ng total RNA. Primers used in the study were obtained from previous literature [28,34]. The qPCR analysis was performed on the QuantStudio ${ }^{\mathrm{TM}} 3$ Real-Time PCR System platform (Thermo Fisher Scientific, Carlsbad, CA, USA). The reaction system was as follows: a total volume of $20 \mu \mathrm{L}$, including cDNA samples, ROX Reference Dye (50X), TB Green ${ }^{\circledR}$ Premix Ex Taq ${ }^{\mathrm{TM}}$ II (Takara, Japan) reagent, $200 \mathrm{nM}$ upstream primer, and $200 \mathrm{nM}$ downstream primer. The reaction conditions were as follows: after pre-denaturation, 40 cycles were performed at $95^{\circ} \mathrm{C} \times 5 \mathrm{~s}, 60^{\circ} \mathrm{C} \times 30 \mathrm{~s}$. $\beta$-actin was used as the internal reference gene to normalize the expression of all target genes, and relative expression was calculated according to the delta-delta Ct method [35]. The primers and related information are shown in Table 1.

Table 1. Primers used for gene expression analysis.

\begin{tabular}{|c|c|c|c|}
\hline Symbol & Gene Name & Primer $\left(5^{\prime}-3^{\prime}\right)$ & $\begin{array}{c}\text { NCBI (National Center for } \\
\text { Biotechnology Information) } \\
\text { Accession Number }\end{array}$ \\
\hline$\beta$-actin & Beta-actin & $\begin{array}{l}\text { F: CGAGCAGGAGATGGGAACC } \\
\text { R: CAACGGAAACGCTCATTGC }\end{array}$ & AF057040.1 \\
\hline gabra1 & $\mathrm{GABA}_{\mathrm{A}}$ receptor, $\alpha 1$ & $\begin{array}{l}\text { F: TCAGGCAGAGCTGGAAGGAT } \\
\text { R: TGCCGTTGTGGAAGAACGT }\end{array}$ & NM_001077326 \\
\hline grin1b & $\begin{array}{c}\text { Glutamate receptor, } \\
\text { ionotropic, N-methyl } \\
\text { D-aspartate } 1 \mathrm{~b}\end{array}$ & $\begin{array}{l}\text { F: CATGAGAACGGCTTCATGG } \\
\text { R: GCCAGCTGCATTTGCTTCC }\end{array}$ & NM_001144131 \\
\hline gria $2 b$ & $\begin{array}{l}\text { Glutamate receptor, } \\
\text { ionotropic, AMPA } 2 b\end{array}$ & $\begin{array}{l}\text { F: ATGACAGTGACCGAGGAC } \\
\text { R: CTTGAAAGAGTGAGCGATA }\end{array}$ & NM_131895 \\
\hline abat & GABA transaminase & $\begin{array}{l}\text { F: GCGTTCAGGCAAAGCTCT } \\
\text { R: GCAGGACGGAAACGGAT }\end{array}$ & NM_201498 \\
\hline $\operatorname{gad} 1 b$ & Glutamate decarboxylase $1 \mathrm{~b}$ & $\begin{array}{l}\text { F: AACTCAGGCGATTGTTGCAT } \\
\text { R: TGAGGACATTTCCAGCCTTC }\end{array}$ & NM_194419 \\
\hline
\end{tabular}

\subsection{Measurement of AChE Activity, GABA, and Glu Concentrations}

The AChE activity, GABA and Glu concentrations were measured using commercial ELISA kits following the manufacturer's manual (No. MM-9110401, MM-9159901 and MM-9160601, respectively, Meimian, Jiangsu, China). Three biological replicates were conducted per treatment per assay.

\subsection{Statistical Analysis}

All data were analyzed using GraphPad Prism 6(GraphPad Software, San Diego, CA, USA). For developmental parameters and ELISA, a one-way analysis of variance (ANOVA) followed by 
Holm-Sidak's multiple comparison test was employed to test for differences between mean values of treatments. One-way ANOVA followed by a Tukey's multiple comparison test was used for gene expression data. All statistical data are expressed as mean \pm standard error (standard error of mean, SEM), and $p$ value $<0.05$ was considered to indicate a significant difference among groups.

\section{Results}

\subsection{Carbamazepine Quantification}

CBZ concentrations in each treatment are shown in Table 2. No significant differences were observed between the nominal and tested values.

Table 2. Carbamazepine (CBZ) concentration (mean $\pm \mathrm{SD}$ ) measured in the exposure solutions.

\begin{tabular}{ccccc}
\hline Conditions & Control & $\mathbf{1} \boldsymbol{\mu g} / \mathrm{L}$ & $\mathbf{1 0} \boldsymbol{\mu g} / \mathrm{L}$ & $\mathbf{1 0 0} \boldsymbol{\mu g} / \mathrm{L}$ \\
\hline Nominal concentration $(\mu \mathrm{g} / \mathrm{L})$ & 0 & 1.00 & 10.00 & 100.00 \\
Measured concentration $(\mu \mathrm{g} / \mathrm{L})$ & No detected & $0.90 \pm 0.02$ & $9.50 \pm 0.22$ & $92.80 \pm 3.50$ \\
\hline
\end{tabular}

\subsection{Early Spontaneous Movement and Development}

No significant changes were observed in hatching rate, heart rate, or body length following exposure to CBZ (Figure 1B-D). However, the early spontaneous movement of embryos was significantly inhibited following exposure to $10 \mu \mathrm{g} / \mathrm{L} \mathrm{CBZ}$ at 28-29 hpf (Figure 1A).

(A)

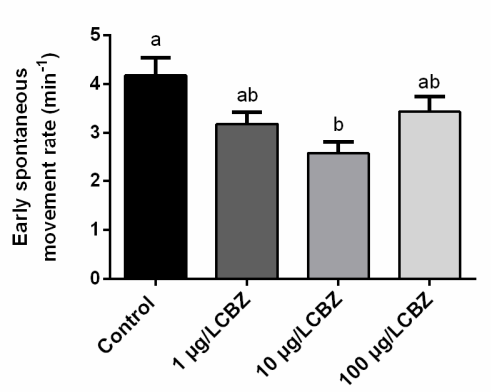

(C)

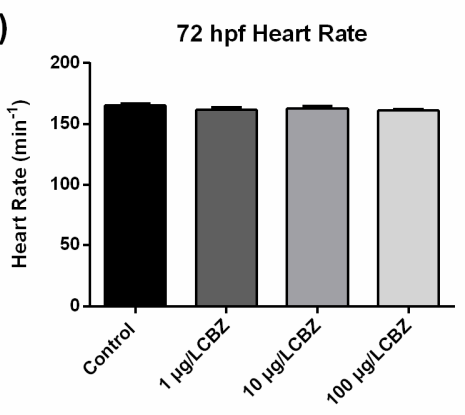

(B)

48-62 hpf Hatching Rate

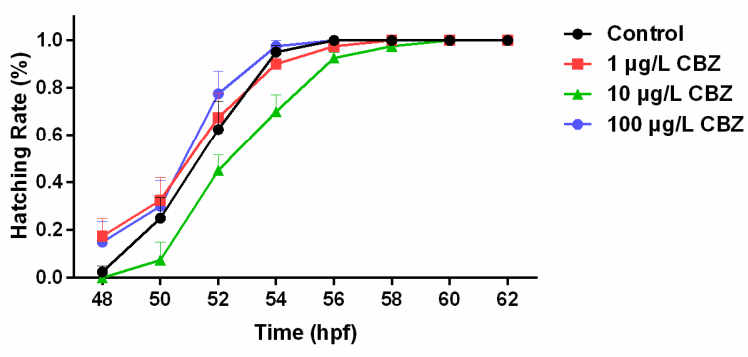

(D)

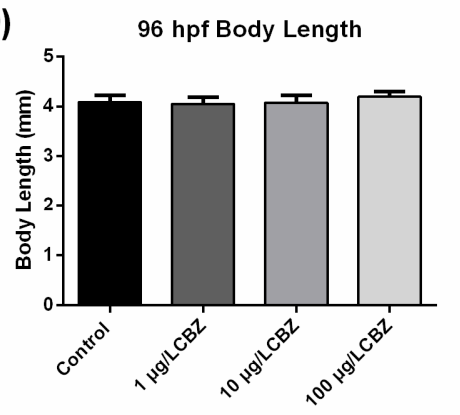

Figure 1. Carbamazepine (CBZ) effects on the development of zebrafish larvae after $6 \mathrm{~d}$ exposure (mean \pm SEM). (A) Early spontaneous movement rate at $28-29 \mathrm{hpf}(n=16)$; (B) Hatching rate at $48-62 \mathrm{hpf}$ $(n=50)$; (C) Heart rate at $72 \mathrm{hpf}(n=12)$; (D) Body length at $96 \mathrm{hpf}(n=10)$. Bars with different letters indicate significant differences between each other $(p<0.05)$. 


\subsection{Gene Expression}

The transcript level of gabra1, grin $1 b$, gria $2 b$, gabra1, abat, and gad1b were measured in zebrafish larvae following exposure to CBZ $(1,10$, and $100 \mu \mathrm{g} / \mathrm{L})$. Most of the genes were inhibited after CBZ exposure (Figure 2). The transcript level of gad1b was significantly downregulated in fish from both the 10 and $100 \mu \mathrm{g} / \mathrm{L} \mathrm{CBZ} \mathrm{exposure} \mathrm{groups;} \mathrm{however,} \mathrm{the} \mathrm{gabara1} \mathrm{transcript} \mathrm{level} \mathrm{was} \mathrm{only} \mathrm{reduced}$ in fish from the $100 \mu \mathrm{g} / \mathrm{L} \mathrm{CBZ}$ exposure group (Figure 2A,E). For grin1b, a significant reduction in transcript level was observed only in the $1 \mu \mathrm{g} / \mathrm{L} \mathrm{CBZ}$ group (Figure 2B). The transcript level of gria $2 b$ was inhibited in fish from the 1 and $100 \mu \mathrm{g} / \mathrm{L}$ CBZ exposure groups, and a significant increase was observed in the $10 \mu \mathrm{g} / \mathrm{L} \mathrm{CBZ} \mathrm{group} \mathrm{(Figure} \mathrm{2C).} \mathrm{The} \mathrm{transcript} \mathrm{level} \mathrm{of} \mathrm{abat} \mathrm{was} \mathrm{reduced} \mathrm{in} \mathrm{fish} \mathrm{from}$ the 1 and $100 \mu \mathrm{g} / \mathrm{L} \mathrm{CBZ} \mathrm{exposure} \mathrm{groups,} \mathrm{and} \mathrm{no} \mathrm{significant} \mathrm{differences} \mathrm{were} \mathrm{observed} \mathrm{in} \mathrm{fish} \mathrm{from} \mathrm{the}$ $10 \mu \mathrm{g} / \mathrm{L} \mathrm{CBZ}$ group (Figure 2D).

(A)

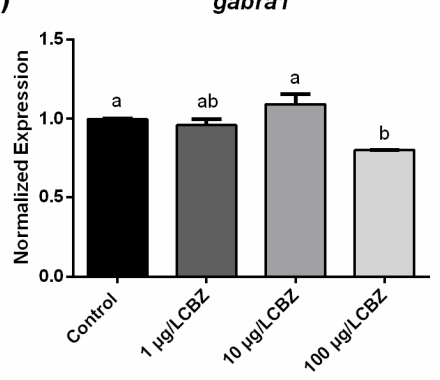

(D)

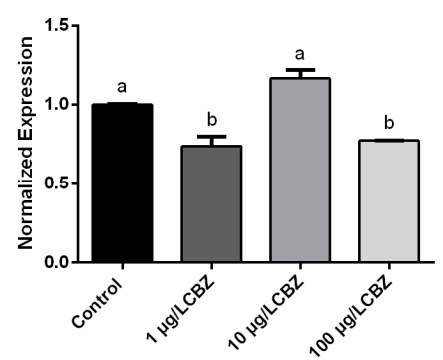

(B)

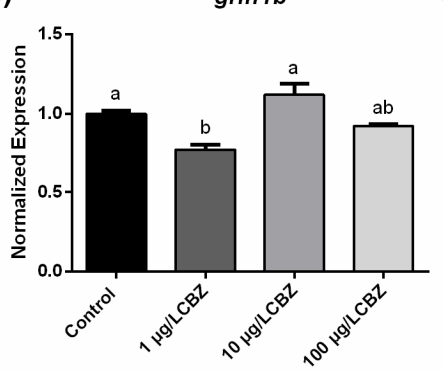

(E)

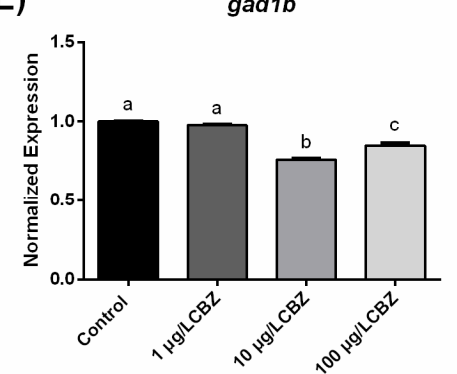

(C)

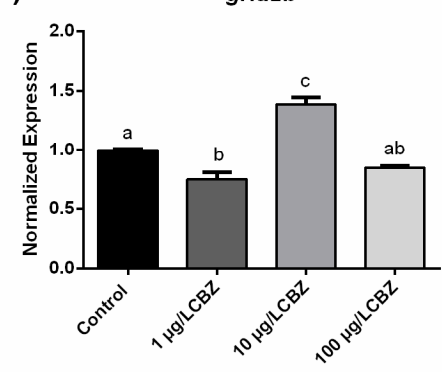

Figure 2. The steady state mRNA levels of (A) gabra1, (B) grin1b, (C) gria2b, (D) abat, (E) gad1b in zebrafish larvae following exposure to CBZ for $6 \mathrm{~d}$ (mean \pm SEM). Bars with different letters indicate significant differences between each other $(n=5 ; p<0.05)$.

\subsection{AChE Activity, GABA and Glu Concentrations Measurement}

After $6 \mathrm{~d}$ exposure, the AChE activity, as well as GABA and glutamate (Glu) concentrations in the zebrafish larval were measured (Figure 3). AChE was significantly increased in zebrafish larvae from both the $10 \mu \mathrm{g} / \mathrm{L}$ and $100 \mu \mathrm{g} / \mathrm{L} \mathrm{CBZ} \mathrm{exposure} \mathrm{groups} \mathrm{(Figure} \mathrm{3A).} \mathrm{Although} \mathrm{no} \mathrm{significant} \mathrm{changes}$ were observed with the highest concentration of CBZ, GABA concentration in the zebrafish larvae was significantly increased in larvae exposed to $1 \mu \mathrm{g} / \mathrm{L} \mathrm{CBZ}$ exposure (Figure 3B). For Glu concentration, a significant decrease was observed in larvae from both the 1 and $100 \mu \mathrm{g} / \mathrm{L} \mathrm{CBZ}$ treatment groups (Figure 3C). 
(A)

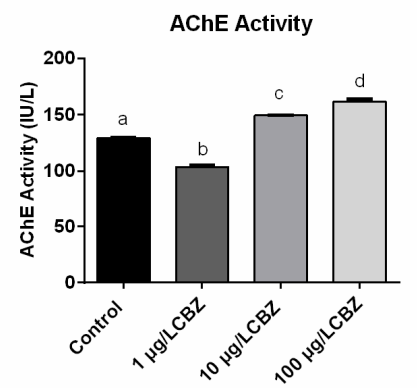

(B)

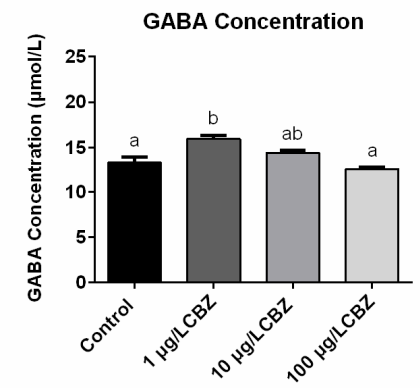

(C)

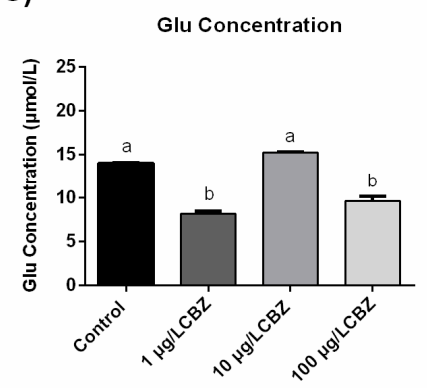

Figure 3. The acetylcholine (AchE) activity, gamma-aminobutyric acid (GABA) and glutamate (Glu) concentrations in the zebrafish larvae after $6 \mathrm{~d}$ of exposure to CBZ (mean \pm SEM). (A) Acetylcholine activity; (B) Gamma-aminobutyric acid concentration; (C) Glutamate concentration. Bars with different letters indicate significant differences among groups $(n=3 ; p<0.05)$.

\section{Discussion}

The current study aimed to investigate the effects of CBZ on the development, early spontaneous movement, and GABA neurotransmitter system in zebrafish larvae after $6 \mathrm{~d}$ exposure. Results showed that exposure to CBZ did not cause significant effects on the development of the zebrafish embryos at the concentrations tested. However, acute CBZ exposure induced alterations in AChE activity and the GABA neurotransmitter system in the zebrafish larvae, suggesting the potential for detrimental effects in the central nervous system during development.

Environmentally relevant concentrations of CBZ have been shown to affect fish more often during chronic exposures compared to acute exposures [14,36,37]. Acute toxicity tests have revealed that CBZ is unlikely to be lethal at environmental levels, with reported LC50 (median lethal concentration) and EC50 (median effective concentration) values approaching $\mathrm{mg} / \mathrm{L}$ levels, and do not exert effects on major physiological processes, such as growth and activity [37]. For example, the $96 \mathrm{~h}$ LC50 values for CBZ in O. latipes is $35.4 \mathrm{mg} / \mathrm{L}$ [36], which is much higher than reported levels in the environment. The $72 \mathrm{~h} \mathrm{LC50}$ for CBZ in zebrafish embryo is $\geq 245 \mathrm{mg} / \mathrm{L}$, and the NOEC (no observed effect concentration) for CBZ in zebrafish embryo on growth retardation has been reported to be above $30.6 \mathrm{mg} / \mathrm{L}$ [17]. In the current study, after a $6 \mathrm{~d}$ exposure to relatively low concentrations of CBZ (1, 10 and $100 \mu \mathrm{g} / \mathrm{L})$, no significant changes in hatching rate, heart rate, or body length were observed. The present study agreed with previous studies, which determined that low exposure concentrations did not affect zebrafish growth [16]. However, the early spontaneous movements of zebrafish larvae were significantly inhibited following $10 \mu \mathrm{g} / \mathrm{L} \mathrm{CBZ} \mathrm{exposure} \mathrm{at} \mathrm{28-29} \mathrm{hpf.} \mathrm{Our} \mathrm{result}$ agreed with a previous study [18] that CBZ can affect the early spontaneous movement of zebrafish. Moreover, similar to our study here, movement percentage and rest percentage of zebrafish larvae were significantly affected at lower levels of CBZ testing, while no effects were detected with the highest CBZ concentration [18]. Taken together, studies suggest that the effects of CBZ on the behavior of zebrafish larvae is non-linear nor dose-dependent. This may be related to a threshold between compensatory responses at lower levels of exposure and higher, potentially more toxic, concentrations. Nevertheless, studies should investigate further jobs and temporal specific responses to CBZ [38].

$\mathrm{AChE}$ hydrolyzes the neurotransmitter acetylcholine, acting to reduce synaptic transmission [39]. Unlike other neurotoxic compounds which can inhibit AChE activity, our study, in conjunction with previous investigations, demonstrates that CBZ can induce AChE activity in fish [16]. This discrepancy between CBZ and other neurotoxic agents may be related to specific mechanisms associated with CBZ. In response to an increase in AChE activity, a subsequent downregulation of acetylcholine receptors can occur [40]; this may explain, in part, the decrease of early spontaneous movement. It is worth noting that $10 \mu \mathrm{g} / \mathrm{L} \mathrm{CBZ} \mathrm{had} \mathrm{a} \mathrm{significant} \mathrm{impact} \mathrm{on} \mathrm{spontaneous} \mathrm{movement} \mathrm{and} \mathrm{AChE} \mathrm{activity,}$ but no effect was observed at a higher dose $(100 \mu \mathrm{g} / \mathrm{L})$. The altered AChE activity in fish following exposure to pharmaceuticals may be related to the complex relationships between the cholinergic 
system and the exposure concentration [41]. For example, after exposure to another psychotropic drug, fluoxetine (50 and $200 \mu \mathrm{g} / \mathrm{L}$ ), for $42 \mathrm{~d}$, only one dose of those tested $(50 \mu \mathrm{g} / \mathrm{L})$ caused an increase of AChE activity following chronic exposure in Pseudorasbora parva [41]. Thus, the relationship between pharmaceutical exposure and AChE activity in larval fish is still unclear and may relate to the balance between therapeutic and toxic doses.

Excitatory (Glu) and inhibitory (GABA) neurotransmitters regulate activity and are involved in integrating signals from the periphery [28,42]. In the current study, the concentrations of GABA and Glu in zebrafish larvae were altered by CBZ exposure. One limitation of the current study is that it is not possible to isolate these effects specifically to the brain as whole larval fish were measured for neurotransmitter levels. Nevertheless, our data suggest that CBZ exposure may result in an imbalance between excitatory and inhibitory neurotransmission based upon altered receptor expression as well as biosynthetic enzymes. Taken together, changes in brain GABA are expected to contribute to the persistence of deficiencies in locomotor activity reported in studies using zebrafish [43-45].

As an agonist of the GABA receptor in humans [18], it is noteworthy to point out that CBZ significantly inhibited gabra1 and grin $1 b$ transcript levels in the zebrafish larvae. This response may reflect alternative mechanisms of $\mathrm{CBZ}$ in fish compared to mammals, or it may be a compensatory response to over-activation of $\mathrm{GABA}_{\mathrm{A}}$ receptors. $\mathrm{GABA}_{\mathrm{A}}$ receptor activation is also involved in long-term potentiation and mediates connections that foster learning and memory [46]. The Gabra1 receptor subunit is localized at synapses in mature neurons and is structurally critical for the formation of ionic channels [47]. Recent studies have shown that $\mathrm{GABA}_{\mathrm{A}}$ receptor expression is altered by environmental contaminants, such as phenazepam, which can also lead to abnormal regulation of feeding behavior [44]. Moreover, abat and gad1b, two enzymes involved in regulating glutamate-GABA metabolic pathways, were also inhibited by CBZ exposure. Glutamic acid decarboxylase 1 or Gad1b, is a major determinant of GABA levels. Gad1 is responsible for catalyzing the production of GABA from glutamate [48]. As reported, inhibition of Gad by (D,L)-allylglycine may lead to GABA depletion, seizures and neuronal damage in zebrafish [49]. As such, CBZ induced downregulation of GABA receptors and metabolic enzymes involved in the synthesis and degradation of GABA may lead to neurotoxicity and abnormal alteration in behavior in zebrafish.

To summarize, many endpoints measured here did not show a linear and dose-dependent effect. This may be due to the different pathways associated with pharmaceutical MoA or general toxicity of a contaminant. Pharmaceuticals have appropriate dosage and courses of treatment, and there is a balance between therapeutic effect and toxicity. It is reported that humans can respond to low doses of CBZ rapidly [50]. Here, we assessed toxicity of CBZ to zebrafish embryos/larvae, and a limitation is that a short exposure time was examined. Moreover, variability in biological response makes it challenging to link broad molecular, biochemical, and morphological endpoints together in a linear fashion. As such, the links that are made amongst endpoints should be interpreted with caution, and our goal here is to propose a working hypothesis for adverse responses in zebrafish to CBZ. However, each biological response may be independent from one another and may not involve interrelated mechanisms. Additional studies are needed to better define the relationship between GABA signaling and behaviors induced by pharmaceutical exposures.

\section{Conclusions}

In conclusion, our results suggest that exposure to low concentrations of CBZ can lead to decreased early spontaneous movement in zebrafish embryos. The increase in $\mathrm{AChE}$ activity is proposed to be related to these effects in zebrafish embryos but there are likely other mechanisms as well. Moreover, the modulation of the GABAergic neurotransmitter system at the transcript and metabolite level suggests that, as a human use antiepileptic drug that acts as an agonist of the $\mathrm{GABA}_{\mathrm{A}}$ receptor in humans, CBZ can also induce alterations in the GABA neurotransmitter system in fish. Overall, this study improves understanding of the neurotoxicity and behavioral toxicity of fish exposed to 
CBZ, and generates data to be used to understand mechanisms of action that underlie antiepileptic drug exposures.

Author Contributions: Conceptualization, H.C.; methodology, H.C. and H.Y.; software, H.Y.; writing—original draft preparation, H.C.; writing-review and editing, Y.Z., X.G., and C.J.M.; supervision, X.G.; funding acquisition, H.C. and Y.Z. All authors have read and agreed to the published version of the manuscript.

Funding: This work was supported by the National Key Research and Development Program of China (2020YFD0900505), the National Natural Science Foundation of China (No.41907222), Natural Science Foundation of Jiangsu Province (Grant No. BK20170109), Science and Technology Major Project of Inner Mongolia (No. ZDZX2018054), the special fund from Key Laboratory of Drinking Water Science and Technology, Research Center for Eco-Environmental Sciences, Chinese Academy of Sciences (Project No. 20K05KLDWST) and State Key Laboratory of Developmental Biology of Freshwater Fish (2020KF007).

Conflicts of Interest: The authors declare no conflict of interest.

\section{References}

1. Daughton, C.G.; Ternes, T.A. Pharmaceuticals and personal care products in the environment: Agents of subtle change? Environ. Health Perspect 1999, 107 (Suppl 6), 907-938. [CrossRef] [PubMed]

2. Li, Y.; Niu, X.; Yao, C.; Yang, W.; Lu, G. Distribution, Removal, and Risk Assessment of Pharmaceuticals and Their Metabolites in Five Sewage Plants. Int. J. Environ. Res. Public Health 2019, 16, 4729. [CrossRef] [PubMed]

3. Liu, N.; Jin, X.; Feng, C.; Wang, Z.; Wu, F.; Johnson, A.C.; Xiao, H.; Hollert, H.; Giesy, J.P. Ecological risk assessment of fifty pharmaceuticals and personal care products (PPCPs) in Chinese surface waters: A proposed multiple-level system. Environ. Int. 2020, 136, 105454. [CrossRef] [PubMed]

4. Liu, J.L.; Wong, M.H. Pharmaceuticals and personal care products (PPCPs): A review on environmental contamination in China. Environ. Int. 2013, 59C, 208-224. [CrossRef] [PubMed]

5. Liu, N.; Jin, X.; Yan, Z.; Luo, Y.; Feng, C.; Fu, Z.; Tang, Z.; Wu, F.; Giesy, J.P. Occurrence and multiple-level ecological risk assessment of pharmaceuticals and personal care products (PPCPs) in two shallow lakes of China. Environ. Sci. Eur. 2020, 32. [CrossRef]

6. Chen, H.; Gu, X.; Zeng, Q.; Mao, Z.; Liang, X.; Martyniuk, C.J. Carbamazepine disrupts molting hormone signaling and inhibits molting and growth of Eriocheir sinensis at environmentally relevant concentrations. Aquat. Toxicol. 2019, 208, 138-145. [CrossRef]

7. Chen, H.; Gu, X.; Zeng, Q.; Mao, Z.; Martyniuk, C.J. Characterization of the GABAergic system in Asian clam Corbicula fluminea: Phylogenetic analysis, tissue distribution, and response to the aquatic contaminant carbamazepine. Comp. Biochem. Physiol. C Toxicol. Pharmacol. 2020, 239, 108896. [CrossRef]

8. Zhang, Y.; Geißen, S.-U.; Gal, C. Carbamazepine and diclofenac: Removal in wastewater treatment plants and occurrence in water bodies. Chemosphere 2008, 73, 1151-1161. [CrossRef]

9. Xie, Z.; Lu, G.; Liu, J.; Yan, Z.; Ma, B.; Zhang, Z.; Chen, W. Occurrence, bioaccumulation, and trophic magnification of pharmaceutically active compounds in Taihu Lake, China. Chemosphere 2015, 138, 140-147. [CrossRef]

10. Ferrer, I.; Thurman, E.M. Analysis of 100 pharmaceuticals and their degradates in water samples by liquid chromatography/quadrupole time-of-flight mass spectrometry. J. Chromatogr. A 2012, 1259, 148-157. [CrossRef]

11. Miao, X.-S.; Metcalfe, C.D. Determination of carbamazepine and its metabolites in aqueous samples using liquid chromatography-Electrospray tandem mass spectrometry. Anal. Chem. 2003, 75, 3731-3738. [CrossRef] [PubMed]

12. Liu, J.; Lu, G.; Xie, Z.; Zhang, Z.; Li, S.; Yan, Z. Occurrence, bioaccumulation and risk assessment of lipophilic pharmaceutically active compounds in the downstream rivers of sewage treatment plants. Sci. Total Environ. 2015, 511, 54-62. [CrossRef] [PubMed]

13. Chen, H.; Zha, J.; Liang, X.; Li, J.; Wang, Z. Effects of the human antiepileptic drug carbamazepine on the behavior, biomarkers, and heat shock proteins in the Asian clam Corbicula fluminea. Aquat. Toxicol. 2014, 155, 1-8. [CrossRef] [PubMed] 
14. Chen, H.; Gu, X.; Zeng, Q.; Mao, Z. Acute and Chronic Toxicity of Carbamazepine on the Release of Chitobiase, Molting, and Reproduction in Daphnia similis. Int. J. Environ. Res. Public Health 2019, 16, 209. [CrossRef]

15. Fraz, S.; Lee, A.H.; Wilson, J.Y. Gemfibrozil and carbamazepine decrease steroid production in zebrafish testes (Danio rerio). Aquat. Toxicol. 2018, 198, 1-9. [CrossRef]

16. da Silva Santos, N.; Oliveira, R.; Lisboa, C.A.; Mona, E.P.J.; Sousa-Moura, D.; Camargo, N.S.; Perillo, V.; Oliveira, M.; Grisolia, C.K.; Domingues, I. Chronic effects of carbamazepine on zebrafish: Behavioral, reproductive and biochemical endpoints. Ecotoxicol. Environ. Saf. 2018, 164, 297-304. [CrossRef]

17. Van den Brandhof, E.J.; Montforts, M. Fish embryo toxicity of carbamazepine, diclofenac and metoprolol. Ecotoxicol. Environ. Saf. 2010, 73, 1862-1866. [CrossRef]

18. Qiang, L.; Cheng, J.; Yi, J.; Rotchell, J.M.; Zhu, X.; Zhou, J. Environmental concentration of carbamazepine accelerates fish embryonic development and disturbs larvae behavior. Ecotoxicology 2016, 25, 1426-1437. [CrossRef]

19. Yan, S.; Wang, M.; Liang, X.; Martyniuk, C.J.; Zha, J.; Wang, Z. Environmentally relevant concentrations of carbamazepine induce liver histopathological changes and a gender-specific response in hepatic proteome of Chinese rare minnows (Gobiocypris rarus). Environ. Pollut. 2018, 243, 480-491. [CrossRef]

20. Yan, S.; Wang, M.; Zha, J.; Zhu, L.; Li, W.; Luo, Q.; Sun, J.; Wang, Z. Environmentally Relevant Concentrations of Carbamazepine Caused Endocrine-Disrupting Effects on Nontarget Organisms, Chinese Rare Minnows (Gobiocypris rarus). Environ. Sci. Technol. 2018, 52, 886-894. [CrossRef]

21. Galus, M.; Kirischian, N.; Higgins, S.; Purdy, J.; Chow, J.; Rangaranjan, S.; Li, H.; Metcalfe, C.; Wilson, J.Y. Chronic, low concentration exposure to pharmaceuticals impacts multiple organ systems in zebrafish. Aquat. Toxicol. 2013, 132-133, 200-211. [CrossRef] [PubMed]

22. Christen, V.; Hickmann, S.; Rechenberg, B.; Fent, K. Highly active human pharmaceuticals in aquatic systems: A concept for their identification based on their mode of action. Aquat. Toxicol. 2010, 96, 167-181. [CrossRef] [PubMed]

23. Ambrósio, A.F.; Soares-da-Silva, P.; Carvalho, C.M.; Carvalho, A.P. Mechanisms of action of carbamazepine and its derivatives, oxcarbazepine, BIA 2-093, and BIA 2-024. Neurochem. Res. 2002, 27, 121-130. [CrossRef] [PubMed]

24. Potschka, H. Pharmacological treatment strategies: Mechanisms of antiepileptic drugs. Epileptology 2013. [CrossRef]

25. Schoch, P.; Richards, J.; Häring, P.; Takacs, B.; Stähli, C.; Staehelin, T.; Haefely, W.; Möhler, H. Co-localization of $\mathrm{GABA}_{\mathrm{A}}$ receptors and benzodiazepine receptors in the brain shown by monoclonal antibodies. Nature 1985, 314, 168. [CrossRef] [PubMed]

26. Charych, E.I.; Liu, F.; Moss, S.J.; Brandon, N.J. GABA A receptors and their associated proteins: Implications in the etiology and treatment of schizophrenia and related disorders. Neuropharmacology 2009, 57, 481-495. [CrossRef]

27. Dionisio, L.; De Rosa, M.J.; Bouzat, C.; del Carmen Esandi, M. An intrinsic GABAergic system in human lymphocytes. Neuropharmacology 2011, 60, 513-519. [CrossRef]

28. Yan, W.; Li, L.; Li, G.; Zhao, S. Microcystin-LR induces changes in the GABA neurotransmitter system of zebrafish. Aquat. Toxicol. 2017, 188, 170-176. [CrossRef]

29. Zheng, S.; Liu, C.; Huang, Y.; Bao, M.; Huang, Y.; Wu, K. Effects of 2,2' ,4,4'-tetrabromodiphenyl ether on neurobehavior and memory change and bcl-2, c-fos, grin $1 \mathrm{~b}$ and lingo1b gene expression in male zebrafish (Danio rerio). Toxicol. Appl. Pharmacol. 2017, 333, 10-16. [CrossRef]

30. Soghomonian, J.-J.; Martin, D.L. Two isoforms of glutamate decarboxylase: Why? Trends Pharmacol. Sci. 1998, 19, 500-505. [CrossRef]

31. Atama, C.I.; Nnaji, E.C.; Christian Ezeoyili, I.; Udeani, F.O.; Onovo, C.J.; Ike Ossai, N.; Oscar Aguzie, I.; Nwani, C.D. Neuromodulatory and oxidative stress evaluations in African catfish Clarias gariepinus exposed to antipsychotic drug chlorpromazine. Drug. Chem. Toxicol. 2020. [CrossRef]

32. Jia, D.; Li, X.; Du, S.; Xu, N.; Zhang, W.; Yang, R.; Zhang, Y.; He, Y.; Zhang, Y. Single and combined effects of carbamazepine and copper on nervous and antioxidant systems of zebrafish (Danio rerio). Environ. Toxicol. 2020, 35, 1091-1099. [CrossRef] [PubMed]

33. Kimmel, C.B.; Ballard, W.W.; Kimmel, S.R.; Ullmann, B.; Schilling, T.F. Stages of embryonic development of the zebrafish. Dev. Dyn. 1995, 203, 253-310. [CrossRef] 
34. Rico, E.P.; de Oliveira, D.L.; Rosemberg, D.B.; Mussulini, B.H.; Bonan, C.D.; Dias, R.D.; Wofchuk, S.; Souza, D.O.; Bogo, M.R. Expression and functional analysis of $\mathrm{Na}(+)$-dependent glutamate transporters from zebrafish brain. Brain Res. Bull 2010, 81, 517-523. [CrossRef] [PubMed]

35. Livak, K.J.; Schmittgen, T.D. Analysis of Relative Gene Expression Data Using Real-Time Quantitative PCR and the $2^{-\triangle \Delta C T}$ Method. Methods 2001, 25, 402-408. [CrossRef] [PubMed]

36. Kim, Y.; Choi, K.; Jung, J.; Park, S.; Kim, P.-G.; Park, J. Aquatic toxicity of acetaminophen, carbamazepine, cimetidine, diltiazem and six major sulfonamides, and their potential ecological risks in Korea. Environ. Int. 2007, 33, 370-375. [CrossRef] [PubMed]

37. Hampel, M.; Bron, J.E.; Taggart, J.B.; Leaver, M.J. The antidepressant drug carbamazepine induces differential transcriptome expression in the brain of Atlantic salmon, Salmo salar. Aquat. Toxicol. 2014, 151, 114-123. [CrossRef]

38. Zindler, F.; Beedgen, F.; Brandt, D.; Steiner, M.; Stengel, D.; Baumann, L.; Braunbeck, T. Analysis of tail coiling activity of zebrafish (Danio rerio) embryos allows for the differentiation of neurotoxicants with different modes of action. Ecotox Environ. Safe 2019, 186, 109754. [CrossRef]

39. Schetinger, M.R.; Porto, N.M.; Moretto, M.B.; Morsch, V.M.; da Rocha, J.B.; Vieira, V.; Moro, F.; Neis, R.T.; Bittencourt, S.; Bonacorso, H.G.; et al. New benzodiazepines alter acetylcholinesterase and ATPDase activities. Neurochem. Res. 2000, 25, 949-955. [CrossRef]

40. Tõugu, V.; Kesvatera, T. Role of ionic interactions in cholinesterase catalysis. Biochim. Biophys. Acta BBA Protein Struct. Mol. Enzymol. 1996, 1298, 12-30. [CrossRef]

41. Chen, H.; Zeng, X.; Mu, L.; Hou, L.; Yang, B.; Zhao, J.; Schlenk, D.; Dong, W.; Xie, L.; Zhang, Q. Effects of acute and chronic exposures of fluoxetine on the Chinese fish, topmouth gudgeon Pseudorasbora parva. Ecotoxicol. Environ. Saf. 2018, 160, 104-113. [CrossRef] [PubMed]

42. Prange, O.; Wong, T.P.; Gerrow, K.; Wang, Y.T.; El-Husseini, A. A balance between excitatory and inhibitory synapses is controlled by PSD-95 and neuroligin. Proc. Natl. Acad. Sci. USA 2004, 101, 13915. [CrossRef] [PubMed]

43. Ravenelle, R.; Neugebauer, N.M.; Niedzielak, T.; Donaldson, S.T. Sex differences in diazepam effects and parvalbumin-positive GABA neurons in trait anxiety Long Evans rats. Behav. Brain Res. 2014, 270, 68-74. [CrossRef] [PubMed]

44. Snigirov, S.; Sylantyev, S. GABA A receptors activate fish feeding behaviour via two distinct functional pathways. J. Exp. Biol. 2018, 221. [CrossRef] [PubMed]

45. Wu, M.; Qiu, X.; Chen, C.; Chen, K.; Li, M.; Xu, H.; Wu, X.; Shimasaki, Y.; Oshima, Y. Short-term and persistent impacts of sublethal exposure to diazepam on behavioral traits and brain GABA levels in juvenile zebrafish (Danio rerio). Sci. Total Environ. 2020, 740, 140392. [CrossRef] [PubMed]

46. Orger, M.B.; Smear, M.C.; Anstis, S.M.; Baier, H. Perception of Fourier and non-Fourier motion by larval zebrafish. Nat. Neurosci. 2000, 3, 1128-1133. [CrossRef]

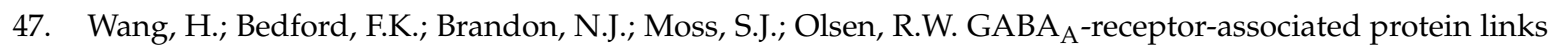
$\mathrm{GABA}_{\mathrm{A}}$ receptors and the cytoskeleton. Nature 1999, 397, 69-72. [CrossRef]

48. Martin, D.L.; Rimvall, K. Regulation of $\gamma$-Aminobutyric Acid Synthesis in the Brain. J. Neurochem. 1993, 60, 395-407. [CrossRef]

49. Leclercq, K.; Afrikanova, T.; Langlois, M.; De Prins, A.; Buenafe, O.E.; Rospo, C.C.; Van Eeckhaut, A.; de Witte, P.A.M.; Crawford, A.D.; Smolders, I.; et al. Cross-species pharmacological characterization of the allylglycine seizure model in mice and larval zebrafish. Epilepsy Behav. 2015, 45, 53-63. [CrossRef]

50. Sands, T.T.; Balestri, M.; Bellini, G.; Mulkey, S.B.; Danhaive, O.; Bakken, E.H.; Taglialatela, M.; Oldham, M.S.; Vigevano, F.; Holmes, G.L.; et al. Rapid and safe response to low-dose carbamazepine in neonatal epilepsy. Epilepsia 2016, 57, 2019-2030. [CrossRef]

Publisher's Note: MDPI stays neutral with regard to jurisdictional claims in published maps and institutional affiliations. 